Check for updates

Cite this: Mater. Adv., 2020 1,689

Received 19th February 2020 Accepted 28th May 2020

DOI: $10.1039 / \mathrm{d} 0 \mathrm{ma} 00038 \mathrm{~h}$

rsc.li/materials-advances

\title{
Ultrafast scale-up synthesis of calcium rod/layer MOFs and luminescence detection of water in organic solvents $\dagger$
}

\author{
Yonghong Xiao, (D) ${ }^{a}$ Zhi-Hong Lin, ${ }^{a}$ Mian Li (D) ${ }^{a b}$ and Xiao-Chun Huang (D) *ab
}

\begin{abstract}
The practical value of metal-organic frameworks (MOFs) which harness great momentum in influencing various fields will be significantly increased if the materials are inexpensive, eco-friendly and can be manufactured at a large scale. Calcium MOFs that satisfy such demands but remain rarely studied in terms of the general applicability of their scale-up synthesis have been investigated in this work. A convenient, low-cost and eco-friendly method for rapid, large-scale synthesis (ca. 80\% yield, over $50000 \mathrm{~kg} \mathrm{~m}^{-3}$ per day within $1 \mathrm{~min}$ ) has been proposed for the production of seven Ca-MOFs with diverse rod/layer-like building units and overall topologies, including a new one (ROD-94) with a rare underlying net. Moreover, one of the products (ROD-95) has been demonstrated to be capable of detecting and quantitatively measuring the water contents in commercial organic solvents (DMF, EtOH and THF) with LOD values of around $1 \%$, and a fluorescent test paper has been implemented accordingly.
\end{abstract}

\section{Introduction}

With the rapid development of society and due to the gradual depletion of natural resources, new materials for use in the energy storage and industrial manufacturing fields need to be developed. Metal-organic frameworks (MOFs), as a class of novel and diverse materials, have been widely studied for their use in gas adsorption and separation, ${ }^{1}$ catalysis, ${ }^{2}$ biomedicine ${ }^{3}$ and so on. To date, various metal sources, especially transition metals, have been used in the construction of MOFs because of their tendency to form secondary building units (SBUs) with regular geometries, which is a prerequisite for predictable overall topologies. ${ }^{4}$ Calcium and its compounds have found various practical applications such as in catalysis ${ }^{5}$ and $\mathrm{CO}_{2}$ capture $^{6}$ and, more importantly, these materials are cheap, biocompatible and eco-friendly. However, MOFs built from calcium ions remain less explored, even though they are valuable in catalysis, ${ }^{7}$ gas separation, ${ }^{8}$ biomedicine, ${ }^{9}$ sensing ${ }^{10}$ and so on.

Scale-up manufacturing acts as a bridge between laboratorial and industrial syntheses. ${ }^{11}$ Solvothermal synthesis, which is one of most common synthetic methods for preparing MOFs in a lab,

\footnotetext{
${ }^{a}$ Department of Chemistry and Key Laboratory for Preparation and Application of Ordered Structural Materials of Guangdong Province, Shantou University, Guangdong 515063, China. E-mail: xchuang@stu.edu.cn

${ }^{b}$ Chemistry and Chemical Engineering Guangdong Laboratory, Shantou 515031, China

$\dagger$ Electronic supplementary information (ESI) available: Experimental details and supporting figures tables. CCDC 1979626 for ROD-94. For ESI and crystallographic data in CIF or other electronic format see DOI: 10.1039/d0ma00038h
}

is unpractical for magnifying the reaction scale due to its disadvantages of long duration, high consumption, and low safety. In order to overcome these shortcomings, a number of new techniques including mechanochemical synthesis, ${ }^{12}$ flow synthesis $^{13}$ and atomic layered deposition ${ }^{14}$ were developed in the past two decades. Although these methods are suitable for producing MOFs with higher space-time yields (STYs) and lower energy costs, purchasing and maintaining the required instruments is still expensive. Recently, several reports regarding simple salt-based room temperature synthesis were published, ${ }^{15}$ but these included only isolated examples, thus lacking a demonstration of general applicability. Herein we focus on developing a simple, lowcost and general method for the rapid and large-scale synthesis of calcium MOFs.

Notably, the variability in the coordination geometry of calcium and its preference to form diverse infinite $\mathrm{SBUs}^{4 c}$ are the obstacles that need to be tackled in order to achieve this goal. Calcium ions, usually considered to be a hard acid with a high charge density, are subject to severe solvation effects in solution due to their oxophilic nature. ${ }^{16}$ Therefore, oxygencontaining solvents may compete with metal-ligand reactions and influence the final structure and sample crystallinity. ${ }^{17}$ The variable coordination number of $\mathrm{Ca}^{2+}$ ions, ${ }^{18}$ ranging most commonly from 6 to 8 , also makes it easy to incorporate $\mathrm{OH}^{-}$ and $\mathrm{O}^{2-}$ generated from solvents used in the formation of metal-oxo clusters. ${ }^{19}$ So far, except for a few with oligonuclear clusters (i.e. with finite SBUs), ${ }^{9,17 c}$ most of the Ca-based MOFs contain rod-like $(1 \mathrm{D})^{8 d, 20}$ and layer-like $(2 \mathrm{D})^{14 a, 19}$ metal-oxo building blocks (i.e. with infinite SBUs). ${ }^{4-f}$ The diversity of 


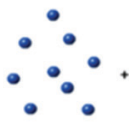

$\mathrm{Ca}(\mathrm{OAC})_{2}$

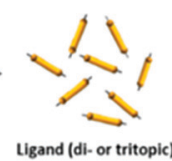

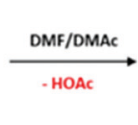

(1)
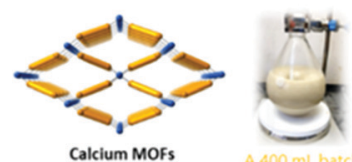

Scheme 1 Illustration of the room-temperature rapid synthesis of calcium MOFs with different ligands used in this study. A photograph of a $400 \mathrm{~mL}$ batch synthesis of $\mathrm{CaNH}_{2}$ PTA (ROD-95) is also shown

synthetic procedures and structural types reported in the literature makes it challenging to develop a general method for fast scale-up syntheses (Scheme 1).

In this work, calcium acetate was selected as the precursor due to its poor solubility in organic solvents and mediumdependent fast precipitation ability. ${ }^{21}$ The organic ligands chosen included di- and tritopic carboxylates and the targeted MOFs have rod/layer-like SBUs, including a new MOF, namely CaDNBPDC (denoted ROD-94), with a rare topology. By controlling the amount of water, the crystallinity of all seven calcium rod/layer MOFs is maintained during the ultrafast scale-up synthesis. After optimization, a high yield of about $80 \%$ and a STY (space-time yield) of up to $100000 \mathrm{~kg} \mathrm{~m}^{-3}$ per day are achieved. To demonstrate its practical use, the bulk sample of $\mathrm{CaNH}_{2} \mathrm{PTA}$ (denoted as ROD-95) is demonstrated as a fast-response luminescence detector for measuring water content in organic solvents, showing good sensitivity and a limit of detection (LOD) of around 1\%.

\section{Results and discussion}

\section{Scale-up synthesis of calcium MOFs}

Numerous studies on the scale-up, fast and industrial synthesis of MOF materials have been reported due to the vast need for their application in various fields. ${ }^{22}$ For calcium MOFs, however, general and systematic studies of scale-up syntheses are very rare, because their structures are highly solvent-dependent due to the strong solvation effect of calcium ions, which makes the prediction of their structures difficult. Seven calcium MOFs including a newly reported one, CaDNBPDC (ROD-94), were selected to perform studies of the scale-up synthesis (see the experimental details in the ESI $\dagger$ ). $\mathrm{CaNH}_{2} \mathrm{PTA}$ (ROD-95) was first chosen for the study because its ligand, 2-aminophthalic acid, is luminescent and shows charge-transfer properties, thus it has various potential applications. ${ }^{23}$ What's more, the amino group in the ligand can also serve as an active site for basic catalysis and selective gas adsorption. ${ }^{24}$ Previously, $\mathrm{CaNH}_{2} \mathrm{PTA}$ was synthesized under solvothermal conditions with or without the assistance of surfactants, ${ }^{10,20 b}$ which was inconvenient for applications due to the long duration and high temperature required for the synthesis. To minimize the consumption of energy and time while maximizing the yield and STY of the reaction, an optimized procedure for producing gram-scaled $\mathrm{CaNH}_{2} \mathrm{PTA}$ was conducted by facilely mixing the aqueous solution of calcium acetate and $\mathrm{H}_{2} \mathrm{NH}_{2} \mathrm{PTA}$ in DMF at an ambient temperature.
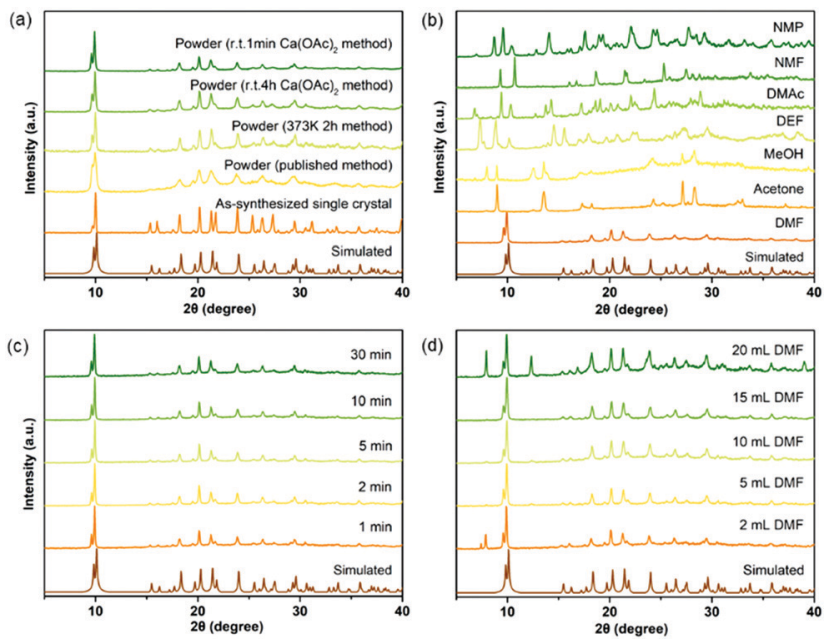

Fig. 1 Optimization of reaction conditions for $\mathrm{CaNH}_{2} \mathrm{PTA}$ (ROD-95) indicated by phase purity: (a) synthetic method, (b) types of organic solvents, (c) reaction time and (d) amount of DMF.

First of all, various approaches were considered in synthesizing $\mathrm{CaNH}_{2} \mathrm{PTA}$ (Fig. 1a). Compared to a previously published method, ${ }^{10}$ facilely heating a DMF solution of the ligand and calcium salt for only $2 \mathrm{~h}$ yielded a yellow crystalline powder with a better crystalline phase, thus successfully shortening the synthesis duration from days to a few hours. Since the energy efficiency of heating is low, room-temperature synthesis is more favorable and practical. ${ }^{15 b, c, 25}$ In order to further shorten the duration of the reaction and crystallization, which is another critical variable affecting productivity and efficiency, tests were carried out within various time durations with the ratio of feed fixed $(1 \mathrm{mmol}$ $\mathrm{H}_{2} \mathrm{NH}_{2} \mathrm{PTA}, 5 \mathrm{~mL}$ DMF, $2 \mathrm{~mL} 0.5 \mathrm{M} \mathrm{Ca}(\mathrm{OAc})_{2}$ solution). After $1 \mathrm{~min}$, the targeted yellow powder was produced in a high yield with good crystallinity, as demonstrated by the well-matched PXRD patterns in Fig. 1c. Micron-scale particles with a uniform clustered morphology were observed under a scanning electron microscope (SEM, Fig. S6, ESI $\dagger$ ). Prolonging the duration from $1 \mathrm{~min}$ to $30 \mathrm{~min}$ and even to $4 \mathrm{~h}$, the phase purity and morphology were maintained (Table S3, ESI $\dagger$ ), which indicated that the reactions were almost completed in $1 \mathrm{~min}$. This could be explained by the fast precipitation process driven by the rather poor solubility of MOFs compared with that of calcium acetate and the moderate basicity of calcium acetate. ${ }^{21 b, 22 e, 26}$ Notably, unlike other MOFs synthesized from the corresponding metal acetates, it takes only a very short time to complete the reaction. One of the possible reasons for this is that, for calcium ions, the affinity towards oxygen atoms is much stronger than that of common transition metal ions, and the $\mathrm{Ca}-\mathrm{O}$ bond is rather ionic; thus, the formation of calcium carboxylate is much easier and faster relative to transition metals. As shown in Fig. 1b, different products were yielded in various solvents due to the high solvation tendency of calcium ions. According to KamletTaft rules, ${ }^{27}$ a solvent with a low $\alpha$ value as well as high $\beta$ and $\pi^{*}$ values (like DMF, DMAc, DMSO, etc.) is suitable for the gelation process, and the high $\pi^{*}$ value is responsible for the solvation step in the formation of coordination compounds. ${ }^{21 a}$ 
The role of DMF was also taken into consideration because it is important in dissolving and deprotonating the ligand ${ }^{28}$ as well as in metal cluster formation, especially for calcium with strong affinity towards oxygen donors, ${ }^{29}$ but the amount of DMF should be reduced due to environmental and economic concerns. When $5 \mathrm{~mL}$ DMF was added, broccoli-like crystallites (Fig. S7, ESI $\dagger$ ) with well-matched diffraction patterns could be obtained (Fig. 1d). This uniformity was preserved up to $15 \mathrm{~mL}$ DMF. Because of the poor solubility of calcium acetate in DMF and that of 2-aminoterephthalic acid in water, a small amount of residuals started to appear when the DMF amount was less than $5 \mathrm{~mL}$ or more than $15 \mathrm{~mL}$, suggesting the precipitation of unreacted starting materials. Further investigation on the morphology of the as-synthesized microscale crystals showed that each particle was constituted by smaller stacked crystals, which were around $100 \mathrm{~nm}$ in size (Fig. S7, ESI $\dagger$ ). From $5 \mathrm{~mL}$ to $15 \mathrm{~mL}$, the yields remained around $83 \%$ (Table S4, ESI $\dagger$ ), which indicated that the amount of DMF was irrelevant to the productivity of $\mathrm{CaNH}_{2} \mathrm{PTA}$, and thus the optimized amount is set at $5 \mathrm{~mL}$ in the following experiments.

Next, a series of control experiments were conducted to examine the influence of adding different amounts of $\mathrm{Ca}(\mathrm{OAc})_{2}$ solution. While the amount of the ligand was fixed at $1 \mathrm{mmol}$ and the volume of DMF was set at $5 \mathrm{~mL}$, the maximal yield ( $\sim 84 \%$ ) could be obtained with the addition of $2 \mathrm{~mL}$ calcium solution (containing $1 \mathrm{mmol} \mathrm{Ca}{ }^{2+}$ ) (Table S5, ESI $\dagger$ ). In addition, the morphology of the products changed dramatically upon the addition of different amounts of acetate $(0.5-4 \mathrm{~mL})$, as shown in Fig. S8 (ESI $\dagger$ ), ranging from needle clusters to dense block crystals. This interesting phenomenon is probably due to the mineralization effect of excess acetate salts, which plays an important role in the crystallization of MOFs and so on. ${ }^{30}$

Considering all the aforementioned factors, an optimized synthetic recipe $\left(1 \mathrm{mmol}\right.$ ligand, $5 \mathrm{~mL} \mathrm{DMF}, 2 \mathrm{~mL} \mathrm{Ca}(\mathrm{OAc})_{2}$ solution in $1 \mathrm{~min}$ ) was proposed. In order to test the applicability of this method in the large-scale synthesis of $\mathrm{CaNH}_{2} \mathrm{PTA}$, a $400 \mathrm{~mL}$ batch (upscaled 60 times, Fig. S9a, ESI $\dagger$ ) was chosen as an example. The resultant powder still maintained a good crystal phase and purity, which indicated that such a method is suitable for scale-up synthesis (Fig. S9b, ESI $\dagger$ ). The proposed approach is mildly implemented at room temperature and ambient pressure within $1 \mathrm{~min}$, and the only by-product is acetic acid, which is eco-friendly. Furthermore, the yield of $\mathrm{CaNH}_{2}$ PTA is about $84 \%$, and the STY $\left(51000 \mathrm{~kg} \mathrm{~m}^{-3}\right.$ per day) is also optimistic, which is favorable for industrial production. ${ }^{11 a, 31}$

Furthermore, the general applicability of this optimized, scale-up method was tested by extending it to seven calcium MOFs constructed from various carboxylate ligands and showing different topologies. There are two main reasons for choosing these candidates: ${ }^{32}$ (1) The diversity of ligands is reflected by the choice of linear ligands (e.g. planar linear ligands such as $\mathrm{H}_{2} \mathrm{PTA}$ and twisted ligands such as $\mathrm{H}_{2}$ DNBPDC) and trifurcate ligands which lead to topologically different Ca-MOFs. (2) The diversity of inorganic motifs is reflected by the inclusion of calcium MOFs containing rod (1D) or layer (2D) SBUs. The selected rod MOFs not only display different underlying nets (e.g. with common sra and irl topologies) ${ }^{4 c}$ but also contain building units of different shapes (e.g. straight and helical rod SBUs). ${ }^{4 d-f}$ In particular, the newly synthesized MOF, CaDNBPDC (ROD-94), exhibits very rare two-way rods (i.e. the rod SBUs extend along two nonparallel directions) in the final vbb topology (Fig. S1 and S2, ESI $\dagger$ ), which was not observed in any crystal structure. ${ }^{4 g}$

Fig. 2 presents all seven structures and the morphology and crystallinity of the large-scale products. The XRD patterns of these upscaled-synthesized Ca-MOFs were consistent with the simulated ones. The thermal stability of the powders was also proved by temperature-dependent PXRD and thermogravimetric tests (Fig. S4 and S5, ESI $\dagger$ ), which is consistent with the results reported previously. ${ }^{19,20 b}$ Besides, the IR (Fig. S3, $\mathrm{ESI} \dagger$ ) and elemental analysis results all confirmed the purity of the products. The yields and space-time yields (STYs) of all 7 MOFs are summarized in Table 1 . The yields of calcium MOFs synthesized using this method were high (above 85\%), except for CaBTC (60\%), and the space-time yields all exceed $50000 \mathrm{~kg} \mathrm{~m}^{-3}$ per day. All in all, the proposed method is suitable for upscaled factorial production, and it might be useful for the synthesis of other MOFs for different applications.

\section{Luminescence detection of water in organic solvents}

Water is involved in metabolism and maintains a state of inner balance in creatures. However, from a chemical research point of view, water is an important reactant/solvent but sometimes even a trace amount of water can ruin a reaction, e.g. by causing the decomposition of inorganic compounds, the deactivation of the catalyst, the failure of a moisture-sensitive reaction, etc. ${ }^{33}$ Various convenient methods have been developed to detect water/moisture by using luminescent MOFs, yet most of them utilized qualitative sensing only. ${ }^{34}$

For example, a MOF-based visual humidity detector was designed by Dong and co-workers by incorporating CuI clusters, which can spontaneously adsorb water molecules while being placed in the air with a change of color from yellow to reddish brown. ${ }^{35}$ Toda and co-workers developed a humidity sensor by using HKUST-1 showing changes in color and electrical signals when coordinated with water. This sensor has a detection limit of $40 \mathrm{ppbv}$ and a moisture response time of $2.5 \mathrm{~s}$ for $2.5 \mathrm{ppmv} .{ }^{36} \mathrm{In}$ 2017, the Su group developed a double-emitting imidazole functionalized Zn-MOF based sensor, which exhibits an extremely fast response accompanied by a transition from blue fluorescence to green. ${ }^{37}$ However, from a practical application point of view, the size and morphology of MOFs should be considered, which have significant impacts on the sensing performance. To ensure the accuracy of sensing, uniformity in particle size and dispersion is required, which could be guaranteed by using micron- or nanosized MOFs other than grinding large crystals.

In this work, a micron-sized fluorescent $\mathrm{MOF}, \mathrm{CaNH}_{2} \mathrm{PTA}$ (ROD-95), was chosen to detect and quantitatively measure the water content in several organic solvents because it showed stability in common solvents for 3 days (Fig. 3a) and displayed selective luminescence response to water relative to these organic solvents (Fig. 3b). DMF, EtOH and THF were selected 


$$
\begin{gathered}
\text { CaPTA } \\
\text { (rod SBU) }
\end{gathered}
$$

$\mathrm{CaNH}_{2} \mathrm{PTA}$ (ROD-95)

(sra net, rod SBU)
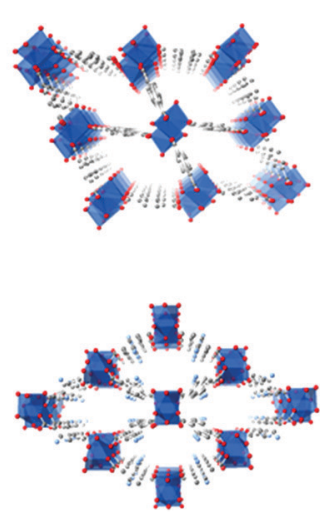

CaDHPTA

(irl net, rod SBU)

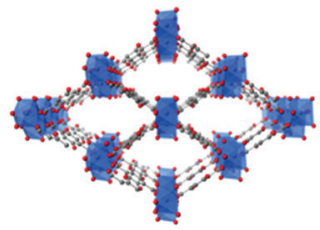

CaNDC

(sra net, rod SBU)

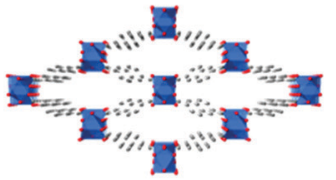

CaBPDC

(layer SBU)

CaBTC

(helical rod SBU)
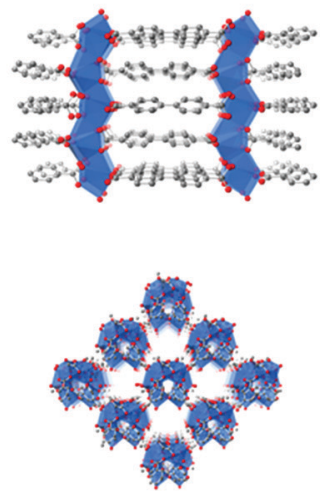
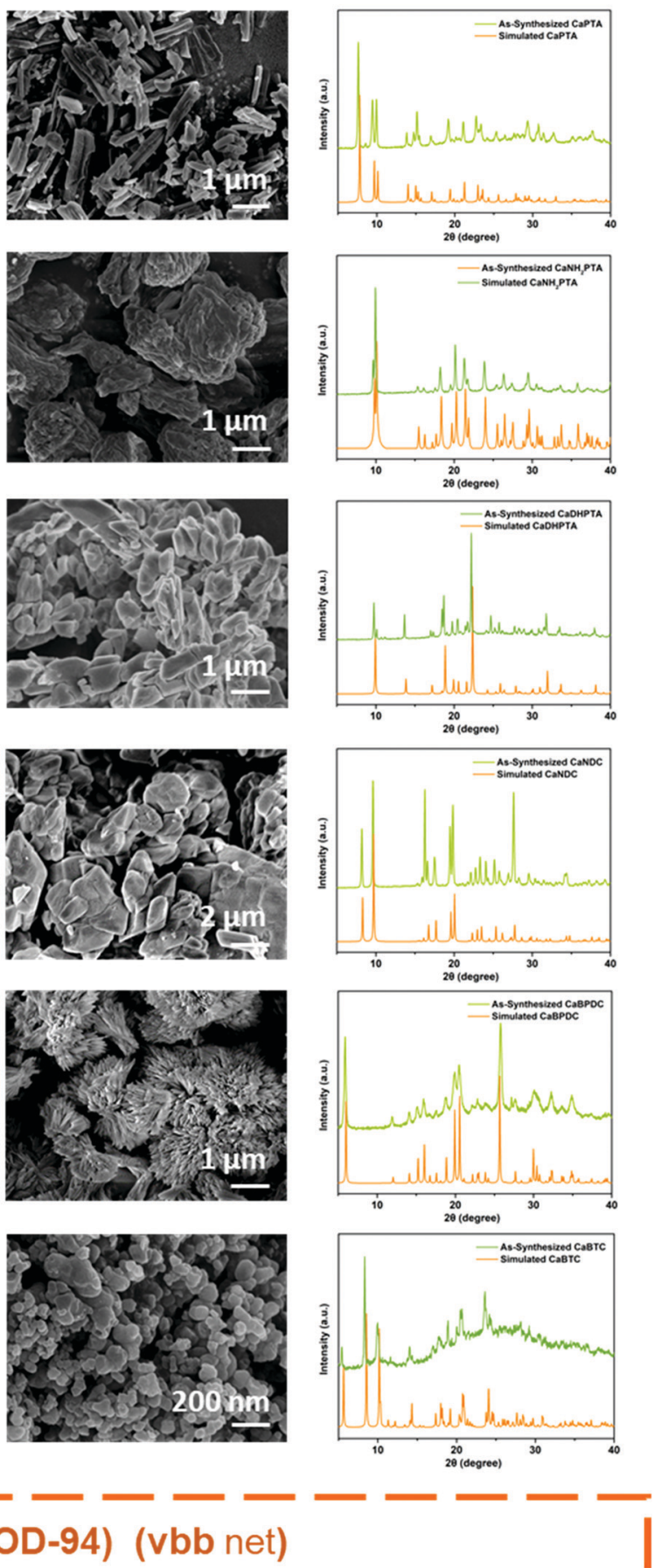

CaDNBPDC (ROD-94) (vbb net)
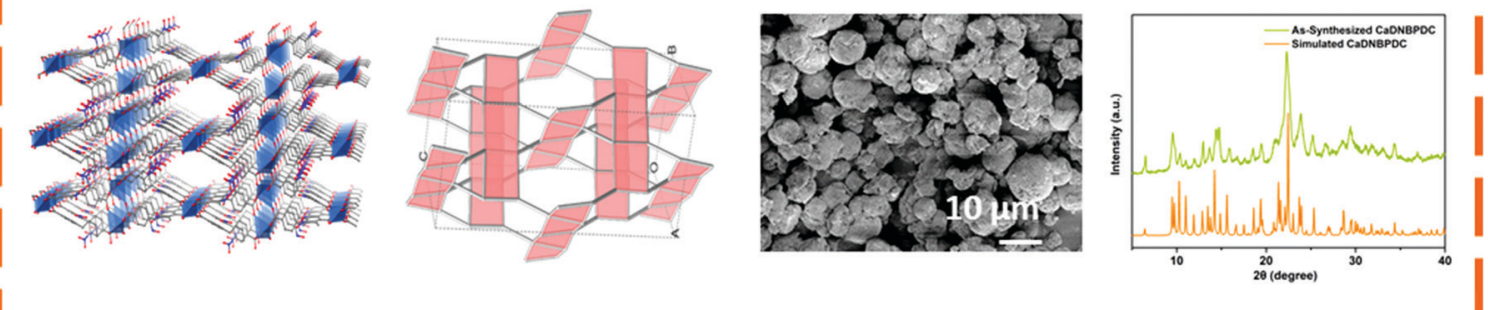

Rare network with 2-way rod SBU!

Fig. 2 The seven selected rod/layer MOFs synthesized by the room-temperature fast scale-up synthesis method. Crystal structures, SEM images, and PXRD patterns are shown in rows. The structure of newly synthesized CaDNBPDC (ROD-94) with an unusual underlying net is highlighted in the red dashed box. 
Table 1 Summary of the results of the scale-up synthesis of calcium MOFs

\begin{tabular}{lllc}
\hline MOF $^{a}$ & Metal SBUs & Yield $^{b}(\%)$ & STY $\left(\mathrm{kg} \mathrm{m}^{-3}\right.$ per day) \\
\hline CaNH $_{2}$ PTA (ROD-95) & 1D & 86 & 51000 \\
CaNDC & 1D & 89 & 60000 \\
CaPTA & 1D & 90 & 58000 \\
CaDHPTA & 1D & 93 & 51000 \\
CaBTC & 1D, helix & 60 & 65000 \\
CaDNBPDC (ROD-94) & 1D, two-way & 96 & 100000 \\
CaBPDC & 2D & 93 & 57000
\end{tabular}

${ }^{a}$ Abbreviations used: $\mathrm{NH}_{2} \mathrm{PTA}=2$-aminoterephthalate; $\mathrm{NDC}=2,6$ naphthalenedicarboxylate; PTA = terephthalate; DHPTA = 2,5-dihydroxyterephthalate; $\mathrm{BTC}=$ benzene-1,3,5-tricarboxylate; DNBPDC $=2,2^{\prime}$ dinitro-4,4'-biphenyldicarboxylate; $\mathrm{BPDC}=4,4^{\prime}$-biphenyldicarboxylate. ${ }^{b}$ Based on ligands.
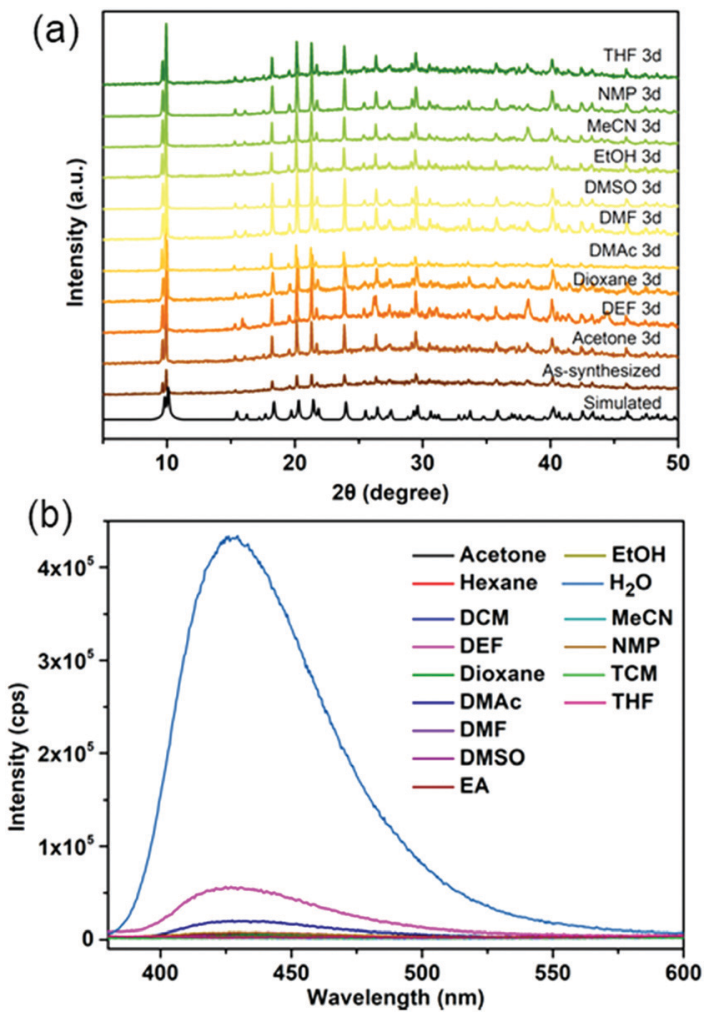

Fig. 3 (a) Solvent stability of $\mathrm{CaNH}_{2}$ PTA (ROD-95) monitored using PXRD patterns after immersion for 3 days; (b) selective sensing of water monitored using the emission spectra of $\mathrm{CaNH}_{2} \mathrm{PTA}$ in supernatants of various solvents in $1 \mathrm{~min}$.

for the detailed study because these are common and essential solvents in organic/inorganic synthesis and in clean energy. ${ }^{38}$

The DMF-water system is taken as an example. Fluorescence sensing tests show that $\mathrm{CaNH}_{2}$ PTA shows an obvious response to DMF solutions with different water contents (Fig. 4a). It can be seen from Fig. $3 \mathrm{~b}$ that as the moisture content decreases, the correlation between fluorescence intensity and maximum emission wavelength can be segmented into three parts: a linear area $(100 \%$ to $46.7 \%)$, an increasing area (40\% to approximately $26.7 \%)$ and an attenuation interval (26.7\% to $0 \%)$. With more than $46 \%$ water content, $\mathrm{CaNH}_{2}$ PTA is completely decomposed. (a)
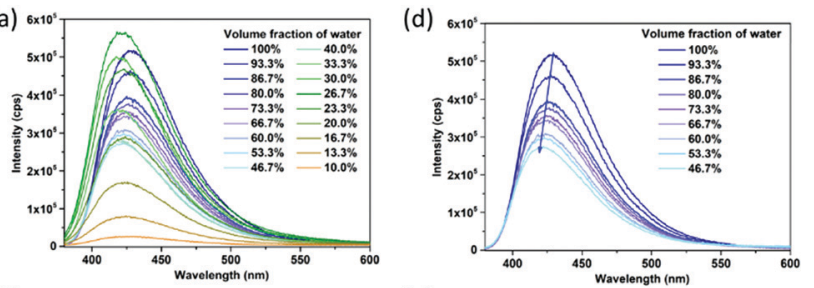

(b)
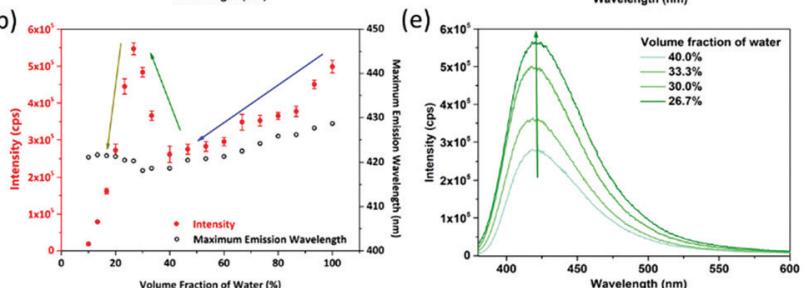

(c)
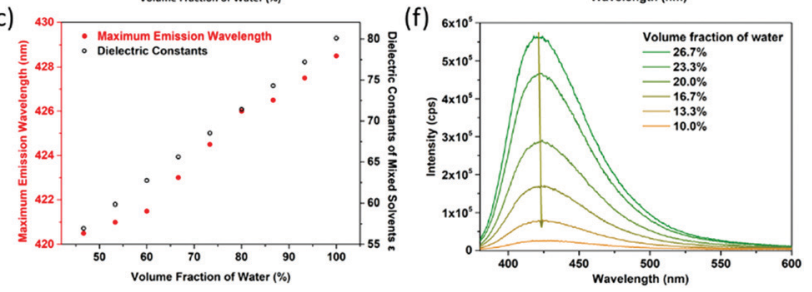

Fig. 4 Luminescence sensing of the water content in DMF through selfdisintegration of $\mathrm{CaNH}_{2} \mathrm{PTA}$ (ROD-95): (a) emission spectra with different water contents, (b) luminescence intensity and maximum emission wavelength as a function of water volume fraction, (c) the relationship between maximum emission wavelength and dielectric constants, and (d-f) emission spectra of the three segments.

As the water content decreases, the fluorescence intensity also decreases gradually and the maximum emission peak of the supernatant is blue-shifted to approximately $425 \mathrm{~nm}$ (Fig. 4d), corresponding to free-ligand emission. ${ }^{23 b, 39}$ Both the maximum emission wavelength and fluorescence intensity exhibit a nearlinear relationship with moisture content (Fig. 4b).

Such an interesting observation could be due to the change in polarity of the mixed solvent. When the moisture content is lowered, the polarity of the solvent decreases. For a polar molecule such as 2-aminoterephthalic acid, the stabilization effect is decreased while the ground-state and excited-state energy levels are elevated and thus the luminescence intensity is lowered. ${ }^{40}$ At the same time, an increase in the polarity of the solvent makes the fluorescent emission peak of the organic ligand with amino groups shift toward a longer wavelength. ${ }^{41}$ In order to confirm this speculation, the dependence of emission energy with the moisture content is correlated with the dielectric constants of the mixed solvents (Fig. 4c). According to Jouyban et al., ${ }^{42}$ the dielectric constant of the mixed solvent is calculated using the following equation:

$$
\varepsilon_{\mathrm{m}}=\varphi_{1} \varepsilon_{1}+\varphi_{2} \varepsilon_{2}=\varphi_{1} \varepsilon_{1}+\left(1-\varphi_{1}\right) \varepsilon_{2}=\varepsilon_{2}+\varphi_{1}\left(\varepsilon_{1}-\varepsilon_{2}\right)
$$

where $\varepsilon_{\mathrm{m}}$ is the dielectric constant of the mixed solvent, and $\varepsilon_{x}$ and $\varphi_{x}(x=1,2)$ are the dielectric constants and the volume (mass or mole) fractions of the solvents, respectively. From Fig. 4c and Fig. S10 (ESI $\dagger$ ), it can be clearly seen that the trend of the dielectric constant value is consistent with that of the maximum emission wavelength and emission intensity. 
For a low water content range (26.7\% to $10 \%)$, the fluorescence intensity decreased parabolically with the decrease in water content (Fig. 4f), and the emission wavelength still remained the same. It is noticed that when the water content was low, partial precipitation occurred showing blue fluorescence. Therefore, it is speculated that the change of fluorescence intensity is related to the amount of $\mathrm{CaNH}_{2}$ PTA decomposed in the mixed solvent, that is related to the ligand concentration in the solution. ${ }^{9 c}$ It can be assumed that the decomposition process is as follows:

$$
\mathrm{Ca}\left(\mathrm{NH}_{2} \mathrm{PTA}\right) \mathrm{DMF} \rightleftharpoons \mathrm{Ca}^{2+}+\mathrm{NH}_{2} \mathrm{PTA}^{2-}+\mathrm{DMF}
$$

Since the calcium MOF can be regarded as an AB-type ionic compound, supposing the ligand concentration decomposed by water is $c\left(\mathrm{NH}_{2} \mathrm{PTA}^{2-}\right)$ and the calcium ion concentration is $c\left(\mathrm{Ca}^{2+}\right)$, the "solubility product" of $\mathrm{CaNH}_{2} \mathrm{PTA}$ is

$K_{\mathrm{sp}}=c\left(\mathrm{NH}_{2} \mathrm{PTA}^{2-}\right) \times c\left(\mathrm{Ca}^{2+}\right) \times c(\mathrm{DMF})=c\left(\mathrm{NH}_{2} \mathrm{PTA}^{2-}\right)^{2} \times$ const.

Therefore, its "solubility" can be written as

$$
S=K_{\mathrm{sp}}{ }^{1 / 2}=c\left(\mathrm{NH}_{2} \mathrm{PTA}^{2-}\right) \times \text { const. }
$$

To obtain the quantified result, a linear fitting was carried out for the dots of the square rooted fluorescence intensity as a function of the moisture content, showing a good linear relationship in the whole range (Fig. S10d, ESI $\dagger$ ).

For the concentration range between $40 \%$ and $26.7 \%$, the lower the moisture content in the solvent, the more the fluorescence is enhanced, and the peak position is almost unchanged (Fig. 4e). This can be explained by the competition between the influences of solubility and polarity.

The overall concentration segment can be seen as the consequence of these two factors; the resulting phenomenon is a reflection of the factor that dominates. When the water content exceeds $40 \%$, the factor of solvent polarity dominates, but, with the decrease in water content, the factor of solubility becomes predominant, which results in a sudden change in luminescence intensity. Similar results were also obtained for the systems with THF or ethanol (Fig. S11-S20, ESI $\dagger$ ).

The limit of detection (LOD) values of the DMF- $\mathrm{H}_{2} \mathrm{O}$, THF$\mathrm{H}_{2} \mathrm{O}$, and EtOH- $\mathrm{H}_{2} \mathrm{O}$ systems were calculated to be $0.34 \%$, $1.59 \%$ and $0.60 \%$, respectively, showing rather high sensitivity. In the literature, a mixed Eu/Dy MOF was recently reported to show a sensitive response to water $(\mathrm{LOD}=0.10 \%) .{ }^{43} \mathrm{Fu}$ and co-workers also reported a Cd-MOF with a water detection limit less than $0.01 \% .{ }^{44}$ However, combining the advantages of ultrafast scale-up synthesis, low cost of materials and energy, short detection time (30 s) and low LOD values, the water detection method reported here is of high practical application value.

\section{Preparation of fluorescent test paper}

In order to make the water detection tool portable for rapid sample testing, a simple fluorescent test paper is implemented. ${ }^{45}$ A onepot synthesized fluorescence indicator based on the absorbent paper was developed by taking advantage of the fast crystal growth of ROD-95. As shown in Fig. 5a, the PXRD patterns of the
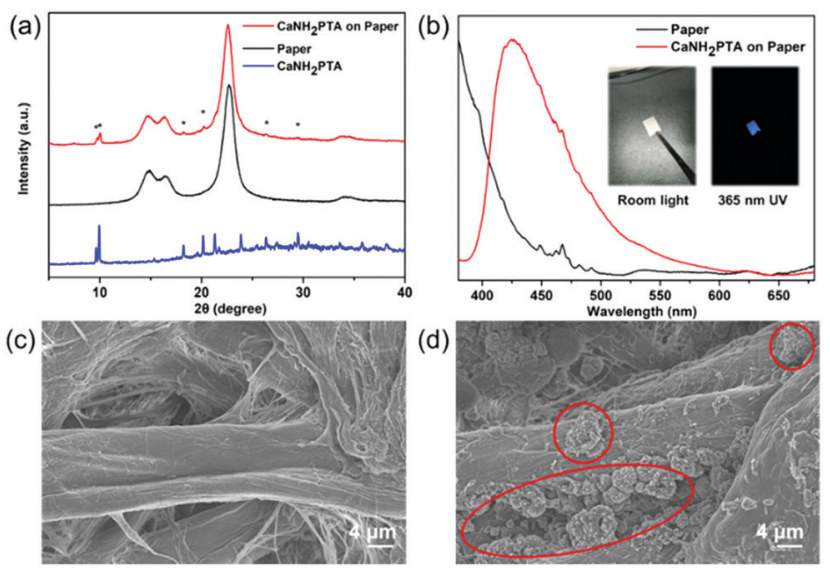

Fig. 5 Preparation of the luminescent test paper: (a) PXRD patterns of the as-made paper loaded with $\mathrm{CaNH}_{2}$ PTA (ROD-95; asterisks represent the peaks of MOF); (b) emission spectra of fluorescent and bare paper (insets show the test paper under room light and $365 \mathrm{~nm}$ UV light) and (c and d) SEM images of the substrate without and with MOF loading (red circles indicate the growth of MOF particles on paper fibres).

paper-MOF composite indicate that the MOF sample is successfully loaded onto the paper. The as-made test paper displays strong blue emission of the MOF under UV light, as indicated by the fluorescence spectrum (Fig. 5b). From the SEM photographs it can be seen that the paper fibres are attached with the small crystallites of the MOF with a particle size of about 8 microns (Fig. 5c and d). All the aforementioned results indicate the successful preparation of paper-MOF composite materials.

\section{Conclusion}

In conclusion, an ultrafast and easy scale-up synthetic method is demonstrated for preparing various calcium rod/layer MOFs which are inexpensive and eco-friendly relative to commonly studied MOFs. The new route developed here is demonstrated to have general applicability covering diverse previously reported materials and a new one (ROD-94); thus, it is encouraged to extend such a highly efficient method to other types of MOFs in large scale synthesis. Thanks to the instability of calcium MOFs in water, we put forward a new working mechanism based on the self-degradation of ROD-95 for the quantitative measurement of water contents in commercially available organic solvents. These findings provide important justification for meeting the urgent need for scalable and sustainable synthesis in the commercialization of MOFs with practical value.

\section{Conflicts of interest}

There are no conflicts to declare.

\section{Acknowledgements}

We gratefully acknowledge the financial support from the NSFC (No. 21571122) and Shantou University. We thank 
Davide M. Proserpio (Università degli studi di Milano) for useful suggestions.

\section{Notes and references}

1 (a) S. S. Han, J. L. Mendoza-Cortes and W. A. Goddard, 3rd, Chem. Soc. Rev., 2009, 38, 1460-1476; (b) J. R. Li, R. J. Kuppler and H. C. Zhou, Chem. Soc. Rev., 2009, 38, 1477-1504; (c) L. J. Murray, M. Dinca and J. R. Long, Chem. Soc. Rev., 2009, 38, 1294-1314; (d) J. R. Li, J. Sculley and H. C. Zhou, Chem. Rev., 2012, 112, 869-932; (e) K. Sumida, D. L. Rogow, J. A. Mason, T. M. McDonald, E. D. Bloch, Z. R. Herm, T. H. Bae and J. R. Long, Chem. Rev., 2012, 112, 724-781.

2 (a) L. Zhu, X. Q. Liu, H. L. Jiang and L. B. Sun, Chem. Rev., 2017, 117, 8129-8176; (b) J. Lee, O. K. Farha, J. Roberts, K. A. Scheidt, S. T. Nguyen and J. T. Hupp, Chem. Soc. Rev., 2009, 38, 1450-1459; (c) L. Ma, C. Abney and W. Lin, Chem. Soc. Rev., 2009, 38, 1248-1256; (d) J. Chen, K. Li, L. Chen, R. Liu, X. Huang and D. Ye, Green Chem., 2014, 16, 2490-2499; (e) A. H. Valekar, K.-H. Cho, S. K. Chitale, D.-Y. Hong, G.-Y. Cha, U. H. Lee, D. W. Hwang, C. Serre, J.-S. Chang and Y. K. Hwang, Green Chem., 2016, 18, 4542-4552; $(f)$ X. Zhang, P. Zhang, C. Chen, J. Zhang, G. Yang, L. Zheng, J. Zhang and B. Han, Green Chem., 2019, 21, 54-58.

3 P. Horcajada, R. Gref, T. Baati, P. K. Allan, G. Maurin, P. Couvreur, G. Ferey, R. E. Morris and C. Serre, Chem. Rev., 2012, 112, 1232-1268.

4 (a) M. O'Keeffe and O. M. Yaghi, Chem. Rev., 2012, 112, 675-702; (b) M. Li, D. Li, M. O'Keeffe and O. M. Yaghi, Chem. Rev., 2014, 114, 1343-1370; (c) A. Schoedel, M. Li, D. Li, M. O'Keeffe and O. M. Yaghi, Chem. Rev., 2016, 116, 12466-12535; (d) N. L. Rosi, J. Kim, M. Eddaoudi, B. Chen, M. O'Keeffe and O. M. Yaghi, J. Am. Chem. Soc., 2005, 127, 1504-1518; (e) M. Li, D. Li, M. O'Keeffe and Z.-M. Su, Chem. Commun., 2015, 51, 12229-12230; $(f)$ Q. Xiao, Y. Wu, M. Li, M. O'Keeffe and D. Li, Chem. Commun., 2016, 52, 11543-11546; ( $g$ ) M. O’Keeffe, M. A. Peskov, S. J. Ramsden and O. M. Yaghi, Acc. Chem. Res., 2008, 41, 1782-1789. Access at: http://rcsr.net/.

5 (a) K. Revunova and G. I. Nikonov, Dalton Trans., 2015, 44, 840-866; (b) M. S. Hill, D. J. Liptrot and C. Weetman, Chem. Soc. Rev., 2016, 45, 972-988; (c) T. E. Stennett and S. Harder, Chem. Soc. Rev., 2016, 45, 1112-1128; (d) M. Fairley, L. Davin, A. Hernan-Gomez, J. Garcia-Alvarez, C. T. O'Hara and E. Hevia, Chem. Sci., 2019, 10, 5821-5831; (e) J. M. Begouin and M. Niggemann, Chemistry, 2013, 19, 8030-8041.

6 (a) Z. Wu, N. Hao, G. Xiao, L. Liu, P. Webley and D. Zhao, Phys. Chem. Chem. Phys., 2011, 13, 2495-2503; (b) L. Zhang, Y. Lu and M. Rostam-Abadi, Phys. Chem. Chem. Phys., 2012, 14, 16633-16643; (c) D. P. Hanak, E. J. Anthony and V. Manovic, Energy Environ. Sci., 2015, 8, 2199-2249; (d) E. S. Sanz-Pérez, C. R. Murdock, S. A. Didas and C. W. Jones, Chem. Rev., 2016, 116, 11840-11876.

7 (a) A. E. Platero-Prats, M. Iglesias, N. Snejko, A. N. Monge and E. Gutiérrez-Puebla, Cryst. Growth Des., 2011, 11,
1750-1758; (b) A. E. Platero Prats, V. A. de la Peña-O’Shea, M. Iglesias, N. Snejko, Á. Monge and E. Gutiérrez-Puebla, ChemCatChem, 2010, 2, 147-149; (c) D. Saha, T. Maity and S. Koner, Eur. J. Inorg. Chem., 2015, 1053-1064; (d) M. AlbertSoriano, P. Trillo, T. Soler and I. M. Pastor, Eur. J. Org. Chem., 2017, 6375-6381.

8 (a) A. M. Plonka, X. Chen, H. Wang, R. Krishna, X. Dong, D. Banerjee, W. R. Woerner, Y. Han, J. Li and J. B. Parise, Chem. Mater., 2016, 28, 1636-1646; (b) D. Banerjee, Z. Zhang, A. M. Plonka, J. Li and J. B. Parise, Cryst. Growth Des., 2012, 12, 2162-2165; (c) K. Noh, N. Ko, H. J. Park, S. Park and J. Kim, CrystEngComm, 2014, 16, 8664-8668; (d) C.-T. Yeh, W.-C. Lin, S.-H. Lo, C.-C. Kao, C.-H. Lin and C.-C. Yang, CrystEngComm, 2012, 14, 1219-1222; (e) L. L. Gong, X. F. Feng, F. Luo, X. F. Yi and A. M. Zheng, Green Chem., 2016, 18, 2047-2055.

9 (a) L.-Q. Wei, J.-Y. Lu, Q.-Q. Li, Y. Zhou, L.-L. Tang and F.-Y. Li, Inorg. Chem. Commun., 2017, 78, 43-47; (b) S. R. Miller, E. Alvarez, L. Fradcourt, T. Devic, S. Wuttke, P. S. Wheatley, N. Steunou, C. Bonhomme, C. Gervais, D. Laurencin, R. E. Morris, A. Vimont, M. Daturi, P. Horcajada and C. Serre, Chem. Commun., 2013, 49, 7773-7775; (c) D. J. Levine, M. I. Gonzalez, C. M. Legendre, T. Runcevski, J. Oktawiec, K. A. Colwell and J. R. Long, ChemMedChem, 2017, 12, 1739-1742.

10 K. S. Asha, G. S. Vaisakhan and S. Mandal, Nanoscale, 2016, 8, 11782-11786.

11 (a) M. Rubio-Martinez, C. Avci-Camur, A. W. Thornton, I. Imaz, D. Maspoch and M. R. Hill, Chem. Soc. Rev., 2017, 46, 3453-3480; (b) P. A. Julien, C. Mottillo and T. Friščić, Green Chem., 2017, 19, 2729-2747.

12 (a) S. Hou, Y. N. Wu, L. Feng, W. Chen, Y. Wang, C. Morlay and F. Li, Dalton Trans., 2018, 47, 2222-2231; (b) K. Uzarevic, T. C. Wang, S. Y. Moon, A. M. Fidelli, J. T. Hupp, O. K. Farha and T. Friščić, Chem. Commun., 2016, 52, 2133-2136; (c) F. Qi, R. S. Stein and T. Friščić, Green Chem., 2014, 16, 121-132.

13 (a) C. Avci-Camur, J. Troyano, J. Pérez-Carvajal, A. Legrand, D. Farrusseng, I. Imaz and D. Maspoch, Green Chem., 2018, 20, 873-878; (b) M. Faustini, J. Kim, G. Y. Jeong, J. Y. Kim, H. R. Moon, W. S. Ahn and D. P. Kim, J. Am. Chem. Soc., 2013, 135, 14619-14626; (c) M. Rubio-Martinez, M. P. Batten, A. Polyzos, K. C. Carey, J. I. Mardel, K. S. Lim and M. R. Hill, Sci. Rep., 2014, 4, 5443; (d) P. A. Bayliss, I. A. Ibarra, E. Pérez, S. Yang, C. C. Tang, M. Poliakoff and M. Schröder, Green Chem., 2014, 16, 3796-3802.

14 (a) J. Penttinen, M. Nisula and M. Karppinen, Chemistry, 2017, 23, 18225-18231; (b) E. Ahvenniemi and M. Karppinen, Chem. Mater., 2016, 28, 6260-6265; (c) J. Penttinen, M. Nisula and M. Karppinen, Chemistry, 2019, 25, 11466-11473.

15 (a) R. B. Lin, L. Li, H. L. Zhou, H. Wu, C. He, S. Li, R. Krishna, J. Li, W. Zhou and B. Chen, Nat. Mater., 2018, 17, 1128-1133; (b) M. Sánchez-Sánchez, N. Getachew, K. Díaz, M. Díaz-García, Y. Chebude and I. Díaz, Green Chem., 2015, 17, 1500-1509; (c) I. Pakamorè, J. Rousseau, C. Rousseau, E. Monflier and P. Á. Szilágyi, Green Chem., 2018, 20, 5292-5298. 
16 D. S. Raja, J.-H. Luo, C.-T. Yeh, Y.-C. Jiang, K.-F. Hsu and C.-H. Lin, CrystEngComm, 2014, 16, 1985-1994.

17 (a) H. Li, X. Fang, S. Ma, Y. Niu, X. Zhao, J. Xu and Z. Duan, Dalton Trans., 2017, 46, 8350-8353; (b) R. K. Vakiti, B. D. Garabato, N. P. Schieber, M. J. Rucks, Y. Cao, C. Webb, J. B. Maddox, A. Celestian, W.-P. Pan and B. Yan, Cryst. Growth Des., 2012, 12, 3937-3943; (c) A. M. Plonka, D. Banerjee and J. B. Parise, Cryst. Growth Des., 2012, 12, 2460-2467.

18 D. Banerjee and J. B. Parise, Cryst. Growth Des., 2011, 11, 4704-4720.

19 C. Volkringer, J. Marrot, G. Férey and T. Loiseau, Cryst. Growth Des., 2008, 8, 685-689.

20 (a) J. Yang, C. A. Trickett, S. B. Alahmadi, A. S. Alshammari and O. M. Yaghi, J. Am. Chem. Soc., 2017, 139, 8118-8121; (b) P.-C. Liang, H.-K. Liu, C.-T. Yeh, C.-H. Lin and V. T. Z. Zima, Cryst. Growth Des., 2011, 11, 699-708.

21 (a) A. Mallick, E.-M. Schön, T. Panda, K. Sreenivas, D. D. Díaz and R. Banerjee, J. Mater. Chem., 2012, 22, 14951-14963; (b) N. Getachew, Y. Chebude, I. Diaz and M. Sanchez-Sanchez, J. Porous Mater., 2014, 21, 769-773; (c) J. G. Flores, E. Sánchez-González, A. Gutiérrez-Alejandre, J. Aguilar-Pliego, A. Martínez, T. Jurado-Vázquez, E. Lima, E. González-Zamora, M. Díaz-García, M. Sánchez-Sánchez and I. A. Ibarra, Dalton Trans., 2018, 47, 4639-4645; (d) J. Kim, A. G. Oliver, G. T. Neumann and J. C. Hicks, Eur. J. Inorg. Chem., 2015, 3011-3018.

22 (a) B. Chen, Z. Yang, Y. Zhu and Y. Xia, J. Mater. Chem. A, 2014, 2, 16811-16831; (b) J. M. Marrett, C. Mottillo, S. Girard, C. W. Nickels, J.-L. Do, G. Dayaker, L. S. Germann, R. E. Dinnebier, A. J. Howarth, O. K. Farha, T. Friščić and C.-J. Li, Cryst. Growth Des., 2018, 18, 3222-3228; (c) E. Zanchetta, L. Malfatti, R. Ricco, M. J. Styles, F. Lisi, C. J. Coghlan, C. J. Doonan, A. J. Hill, G. Brusatin and P. Falcaro, Chem. Mater., 2014, 27, 690-699; (d) P. Silva, S. M. Vilela, J. P. Tome and F. A. Almeida Paz, Chem. Soc. Rev., 2015, 44, 6774-6803; (e) D. Prochowicz, K. Sokolowski, I. Justyniak, A. Kornowicz, D. Fairen-Jimenez, T. Friscic and J. Lewinski, Chem. Commun., 2015, 51, 4032-4035; $(f)$ Y. Pan, Y. Liu, G. Zeng, L. Zhao and Z. Lai, Chem. Commun., 2011, 47, 2071-2073; (g) J.-L. Zhuang, D. Ceglarek, S. Pethuraj and A. Terfort, Adv. Funct. Mater., 2011, 21, 1442-1447.

23 (a) X.-Y. Xu and B. Yan, Sens. Actuators, B, 2016, 230, 463-469; (b) S. Y. Zhu and B. Yan, Dalton Trans., 2018, 47, 1674-1681; (c) J. Aguilera-Sigalat and D. Bradshaw, Chem. Commun., 2014, 50, 4711-4713.

24 (a) B. Zornoza, A. Martinez-Joaristi, P. Serra-Crespo, C. Tellez, J. Coronas, J. Gascon and F. Kapteijn, Chem. Commun., 2011, 47, 9522-9524; (b) P. Rangaraj, S. Parshamoni and S. Konar, Chem. Commun., 2015, 51, 15526-15529; (c) M. A. Nasalevich, M. G. Goesten, T. J. Savenije, F. Kapteijn and J. Gascon, Chem. Commun., 2013, 49, 10575-10577; (d) X. Li, Y. Pi, Q. Hou, H. Yu, Z. Li, Y. Li and J. Xiao, Chem. Commun., 2018, 54, 1917-1920; (e) J. F. Kurisingal, Y. Rachuri, Y. Gu, Y. Choe and D.-W. Park, Inorg. Chem. Front., 2019, 6, 3613-3620; $(f)$ P. Leo, G. Orcajo, D. Briones, A. Rodriguez-Dieguez, D. Choquesillo-Lazarte, G. Calleja and F. Martinez, Dalton Trans., 2019, 48, 11556-11564.
25 (a) S. K. Nandigama, V. R. Bheeram and S. B. Mukkamala, Environ. Chem. Lett., 2018, 17, 447-454; (b) G. Majano, O. Ingold, M. Yulikov, G. Jeschke and J. Pérez-Ramírez, CrystEngComm, 2013, 15, 9885-9892.

26 M. Díaz-García, Á. Mayoral, I. Díaz and M. Sánchez-Sánchez, Cryst. Growth Des., 2014, 14, 2479-2487.

27 M. J. Kamlet, J. L. M. Abbout, M. H. Abraham and R. W. Taft, J. Org. Chem., 1983, 48, 2877-2887.

28 (a) D. J. Tranchemontagne, J. R. Hunt and O. M. Yaghi, Tetrahedron, 2008, 64, 8553-8557; (b) T. He, X. Xu, B. Ni, H. Wang, Y. Long, W. Hu and X. Wang, Nanoscale, 2017, 9, 19209-19215; (c) Y. Zhao, L. Jiang, L. Shangguan, L. Mi, A. Liu and S. Liu, J. Mater. Chem. A, 2018, 6, 2828-2833.

29 L. Han, L. Qin, L. Xu, Y. Zhou, J. Sun and X. Zou, Chem. Commun., 2013, 49, 406-408.

30 (a) F. Wang, H. Guo, Y. Chai, Y. Li and C. Liu, Microporous Mesoporous Mater., 2013, 173, 181-188; (b) C. Xin, H. Zhan, X. Huang, H. Li, N. Zhao, F. Xiao, W. Wei and Y. Sun, $R S C$ $A d v .$, 2015, 5, 27901-27911; (c) M. Jian, B. Liu, R. Liu, J. Qu, H. Wang and X. Zhang, RSC Adv., 2015, 5, 48433-48441.

31 J. Ren, X. Dyosiba, N. M. Musyoka, H. W. Langmi, M. Mathe and S. Liao, Coord. Chem. Rev., 2017, 352, 187-219.

32 (a) D. Kojima, T. Sanada, N. Wada and K. Kojima, RSC Adv., 2018, 8, 31588-31593; (b) M. Mazaj, G. Mali, M. Rangus, E. Žunkovič, V. Kaučič and N. Zabukovec Logar, J. Phys. Chem. C, 2013, 117, 7552-7564; (c) S. N. Zhao, X. Z. Song, M. Zhu, X. Meng, L. L. Wu, S. Y. Song, C. Wang and H. J. Zhang, Dalton Trans., 2015, 44, 948-954; (d) F. Xu, H. Wang, S. J. Teat, W. Liu, Q. Xia, Z. Li and J. Li, Dalton Trans., 2015, 44, 20459-20463; (e) P. Suresh, C. N. Babu, N. Sampath and G. Prabusankar, Dalton Trans., 2015, 44, 7338-7346.

33 (a) T. Mondal, A. K. Bhowmick and R. Krishnamoorti, RSC $A d v .$, 2014, 4, 8649-8656; (b) B. Karimi and P. Fadavi Akhavan, Chem. Commun., 2011, 47, 7686-7688.

34 (a) T. Cheng, J. Hu, C. Zhou, Y. Wang and M. Zhang, Sci. China: Chem., 2016, 59, 929-947; (b) Z. Liao, T. Xia, E. Yu and Y. Cui, Crystals, 2018, 8, 338; (c) W. P. Lustig, S. Mukherjee, N. D. Rudd, A. V. Desai, J. Li and S. K. Ghosh, Chem. Soc. Rev., 2017, 46, 3242-3285; (d) Y. Zhou, D. Zhang, W. Xing, J. Cuan, Y. Hu, Y. Cao and N. Gan, Anal. Chem., 2019, 91, 4845-4851.

35 Y. Yu, X. M. Zhang, J. P. Ma, Q. K. Liu, P. Wang and Y. B. Dong, Chem. Commun., 2014, 50, 1444-1446.

36 S. Ohira, Y. Miki, T. Matsuzaki, N. Nakamura, Y. K. Sato, Y. Hirose and K. Toda, Anal. Chim. Acta, 2015, 886, 188-193.

37 L. Chen, J. W. Ye, H. P. Wang, M. Pan, S. Y. Yin, Z. W. Wei, L. Y. Zhang, K. Wu, Y. N. Fan and C. Y. Su, Nat. Commun., 2017, 8, 15985.

38 (a) G. R. Qu, P. Y. Xin, H. Y. Niu, D. C. Wang, R. F. Ding and H. M. Guo, Chem. Commun., 2011, 47, 11140-11142; (b) P. Y. Xin, H. Y. Niu, G. R. Qu, R. F. Ding and H. M. Guo, Chem. Commun., 2012, 48, 6717-6719; (c) B. Tabah, I. N. Pulidindi, V. R. Chitturi, L. M. Reddy Arava, A. Varvak, E. Foran and A. Gedanken, J. Mater. Chem. A, 2017, 5, 15486-15506; (d) M. N. A. M. Yusoff, N. W. M. Zulkifli, B. M. Masum and H. H. Masjuki, RSC Adv., 2015, 5, 100184-100211; 
(e) Majid M. Heravi, M. Ghavidel and L. Mohammadkhani, RSC Adv., 2018, 8, 27832-27862.

39 (a) J. Cornelio, T. Y. Zhou, A. Alkas and S. G. Telfer, J. Am. Chem. Soc., 2018, 140, 15470-15476; (b) W. Xie, C. Yao, K.-Z. Shao, Y.-H. Xu and Z.-M. Su, New J. Chem., 2018, 42, 20056-20060; (c) M. Rad and S. Dehghanpour, RSC Adv., 2016, 6, 61784-61793.

40 L. Yu, Q. Zheng, H. Wang, C. Liu, X. Huang and Y. Xiao, Anal. Chem., 2020, 92, 1402-1408.

41 (a) X. Ouyang, X. L. Li, L. Ai, D. Mi, Z. Ge and S. J. Su, ACS Appl. Mater. Interfaces, 2015, 7, 7869-7877; (b) S. Zhang, L. Yao, Q. Peng, W. Li, Y. Pan, R. Xiao, Y. Gao, C. Gu,
Z. Wang, P. Lu, F. Li, S. Su, B. Yang and Y. Ma, Adv. Funct. Mater., 2015, 25, 1755-1762.

42 A. Jouyban, S. Soltanpour and H. K. Chan, Int. J. Pharm., 2004, 269, 353-360.

43 H. Li, W. Han, R. Lv, A. Zhai, X. L. Li, W. Gu and X. Liu, Anal. Chem., 2019, 91, 2148-2154.

44 F. Cheng, R. Fu, Y. Wen, Y.-Y. Yang, C. Zeng, Y. Zhang, S. Hu and X. Wu, J. Mater. Chem. C, 2018, 6, 12341-12346.

45 (a) M. Wang, L. Guo and D. Cao, Anal. Chem., 2018, 90, 3608-3614; (b) T. T. Li, L. Liu, M. L. Gao and Z. B. Han, Chem. Commun., 2019, 55, 4941-4944; (c) Z.-P. Dong, J.-J. Zhao, P.-Y. Liu, Z.-L. Liu and Y.-Q. Wang, New J. Chem., 2019, 43, 9032-9038. 